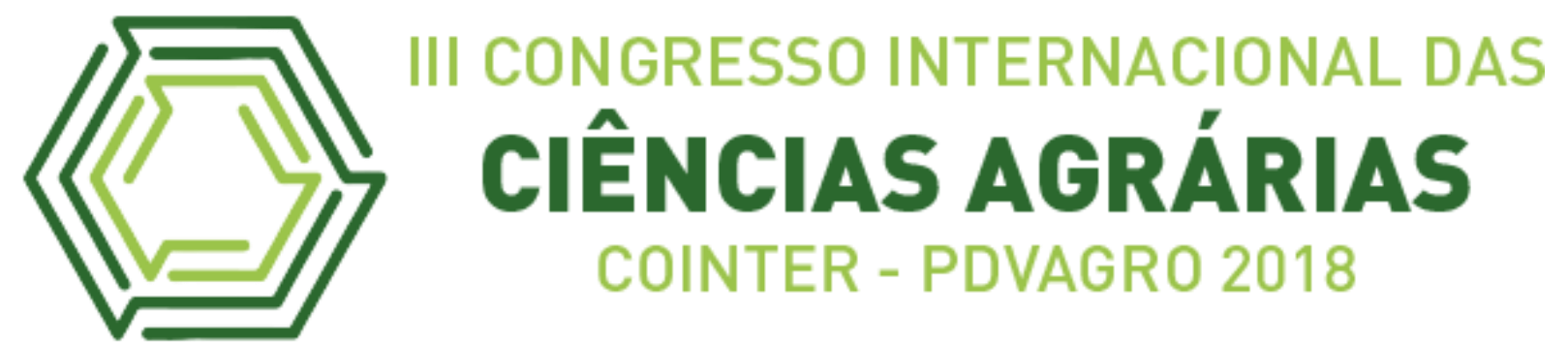

\title{
CONSUMO DE CATETOS (Pecari tajacu) ALIMENTADOS COM NÍVEIS CRESCENTES DE UREIA
}

\section{CONSUMPTION OF CATHETERS (Pecari tajacu) FED WITH GROWING LEVELS OF UREA}

Apresentação: Pôster

\section{DOI: https://doi.org/10.31692/2526-7701.IIICOINTERPDVAGRO.2018.00397}

\section{Introdução}

O cateto é uma das espécies silvestres que possui um grande potencial zootécnico para criação em cativeiro (MENDES, 2008). Esses animais são diferentes dos suínos domésticos, pois, apresentam uma glândula de cheiro no dorso acima da base da cauda, pela ausência da vesícula biliar, pela cauda vestigial e pelos 38 dentes. Dentre outros aspectos, está a compartimentalização do estômago, sendo o pré-estômago composto pela câmara de fermentação e dois sacos cegos e, posteriormente, o estômago glandular que realiza atividades fermentativas e conseqüentemente produção de proteína (SOWLS, 1997).

Por essa característica, torna-se viável a introdução de fontes de nitrogênio não protéico (NNP) que favorecem um maior incremento energético ao animal. De acordo com Swingle et al. (1997) as fontes de nitrogênio (N) mais utilizadas em dietas para ruminantes são os farelos de grãos oleaginosos e os produtos capazes de fornecer nitrogênio na forma não-proteica (NNP), como a ureia. Os farelos proteicos naturais são eficientes na suplementação proteica, mas possuem a desvantagem de ter custo mais elevado por unidade de nitrogênio que as fontes de nitrogênio não proteico (NNP), como a ureia.

Segundo Andriguetto et al. (1988) a ureia contém de $42 \%$ a $45 \%$ de nitrogênio, o que representa um equivalente proteico de $281 \%$, podendo substituir até um terço da proteína total ingerida pelo animal, visando diminuir a utilização de suplementos proteicos, geralmente de preços elevados. Este presente estudo tem como objetivo, avaliar o consumo de catetos em resposta a inclusão da ureia na alimentação.

\section{Fundamentação Teórica}


O cateto (Pecari tajacu) apresenta uma diversidade alimentar facilitando sua criação em cativeiro, onde se adaptam a vários tipos de alimentos desde frutos, raízes, tubérculos e até gramíneas (EDDY, 1961; SOLWS, 1984).

Devido às características no trato digestório, Langes (1979) sugeriu que a digestão em catetos seria semelhante à de um animal ruminante. A fermentação microbiana no préestômago de catetos é importante para seu metabolismo energético. Além do metabolismo energético, esse processo é importante para o balanço nitrogenado/ proteico para os catetos (MENDES, 2008). Segundo Reece (1996) as bactérias e protozoários do rúmen de bovinos e ovinos podem sintetizar seus constituintes nitrogenados usando amônia como principal fonte de nitrogênio. A amônia pode ser derivada da proteína dietética, da ureia da saliva e da ureia que se difunde através da parede do rúmen.

Nogueira Filho et al. (2006) avaliaram a adição de ureia na dieta de catetos em cativeiro até o nível equivalente a $55 \mathrm{~g}$ por $100 \mathrm{~kg}$ de peso vivo e observaram que os animais não exibiram sinais de intoxicação e apresentaram ganho de peso, contudo afirmaram a necessidade de estudos futuros para avaliação do uso da ureia por períodos prolongados, uma vez que foi verificada também um incremente no nível sérico da ureia.

A ureia, associada a uma fonte energética, pode substituir parte dos suplementos proteicos que geralmente entram na composição de um concentrado. A adição de ureia contribui, assim, para a redução do custo da ração, quando esta mistura é realizada na fazenda sob orientação técnica, pois essa fonte fornece proteína de baixo custo. A quantidade de ureia em concentrado é limitada a 2\% e deve ser misturada uniformemente (EMBRAPA, 1997).

\section{Metodologia}

O experimento foi realizado no Centro de Multiplicação de Animais Silvestres (CEMAS) da Universidade Federal Rural do Semi-Árido (UFERSA), no período 15 dias durante o mês de junho de 2018. Foram utilizadas três baias experimentais coletivas com 3 metros de largura e 20 metros de comprimento, contendo $85 \%$ de chão batido exposta ao sol e uma área de aproximadamente $15 \%$ sombreada com piso de concreto, possuindo comedouro e bebedouro. Cada baia abrigou um casal, totalizando em 6 animais adultos ( 3 machos e 3 fêmeas), nascidos e criados no CEMAS, os quais, apresentavam peso médio inicial de 17,24.

As baias foram distribuídas em três tratamentos, variando o nível de inclusão de ureia $(0 \%, 1 \%$ e $2 \%)$ na dieta padrão composta por milho moído, farelo de soja, farelo de trigo e 
complemento mineral. A dieta total diária foi ofertada, considerando $20 \%$ de sobras, durante duas vezes ao dia nos horários de 06:00 e 16:00 horas. As sobras foram pesadas afim de estimar o consumo e ajustar a próxima oferta.

O delineamento experimental utilizado foi inteiramente casualizado. Os dados foram submetidos à análise de regressão para verificação da interação do consumo alimentício em resposta as diferentes doses de ureia, por meio do software SISVAR 5.6 pelo teste de Tukey a $5 \%$ de probabilidade.

\section{Resultados e Discussões}

Durante todo o experimento não foi observado nos catetos sinais de intoxicação. Os animais que receberam ureia, nas proporções de 1,0 e 2,0\% não apresentaram considerável ganho de peso $(\mathrm{P}>0,05)(15,6 ; 17,95 ; 17,75 \mathrm{~kg})$ ao dos animais do tratamento testemunha $(20,45 ; 17,25 \mathrm{~kg})$.

Tabela 1. Média de consumo dos catetos em resposta aos diferentes níveis de uréia. Fonte: Própria

\begin{tabular}{|c|c|c|c|}
\hline \multirow{2}{*}{ Consumo } & \multicolumn{3}{|c|}{ Níveis de uréia (\%) } \\
\hline & 0 & 1 & 2 \\
\hline Manhã & $393,21^{\mathrm{a}}$ & $331,43^{\mathrm{a}}$ & $450,10^{\mathrm{a}}$ \\
\hline Tarde & $488,60^{\mathrm{a}}$ & $392,97^{\mathrm{a}}$ & $514,53^{\mathrm{a}}$ \\
\hline
\end{tabular}

Letras iguais na mesma linha não diferem estatisticamente $(\mathrm{P}>0,05)$.

Não houve interação $(P>0,05)$ do consumo x níveis de ureia. Magalhães et al. (2002) ao trabalharem com níveis de $0 \% ; 0,65 \% ; 1,30 \%$; e $1,95 \%$ de ureia na matéria seca (MS) da dieta total de novilhos de origem leiteira, não verificaram efeito da inclusão de ureia sobre o consumo. O consumo médio voluntário (440,91; 362,20;479,84 g/dia) não apresentou diferença significativa $(\mathrm{p}>0,05)$ para as doses crescentes de ureia $(0 \%, 1 \%, 2 \%)$, respectivamente, sendo o maior valor para o consumo com nível de inclusão de ureia de 2,0\% e o menor valor foi constatado para a dieta contendo 1,0\% de ureia. Durante o experimento o consumo voluntário foi relevante ao esperado, pois Nogueira Filho e Lavorenti (1997) verificaram que animais com peso médio de $21 \mathrm{~kg}$ consumiriam em torno de $500 \mathrm{~g}$ de concentrado/dia. 
Os animais consideravelmente apresentaram um consumo médio voluntário (tabela 1) maior à tarde em comparação com o consumo pela manhã. Um dos fatores que pode ter afetado o consumo alimentar pela manhã foi o estresse, em virtude da movimentação dos funcionários do setor no manejo com os outros animais e/ou práticas realizadas no setor. Segundo Swols (1997), estes animais vivem em grupos estáveis, e os utilizados neste experimento originalmente eram mantidos em grupos de três a cinco animais.

Gráfico 1. Regressão linear entre consumo e diferentes níveis de uréia na alimentação de catetos. Fonte: Própria

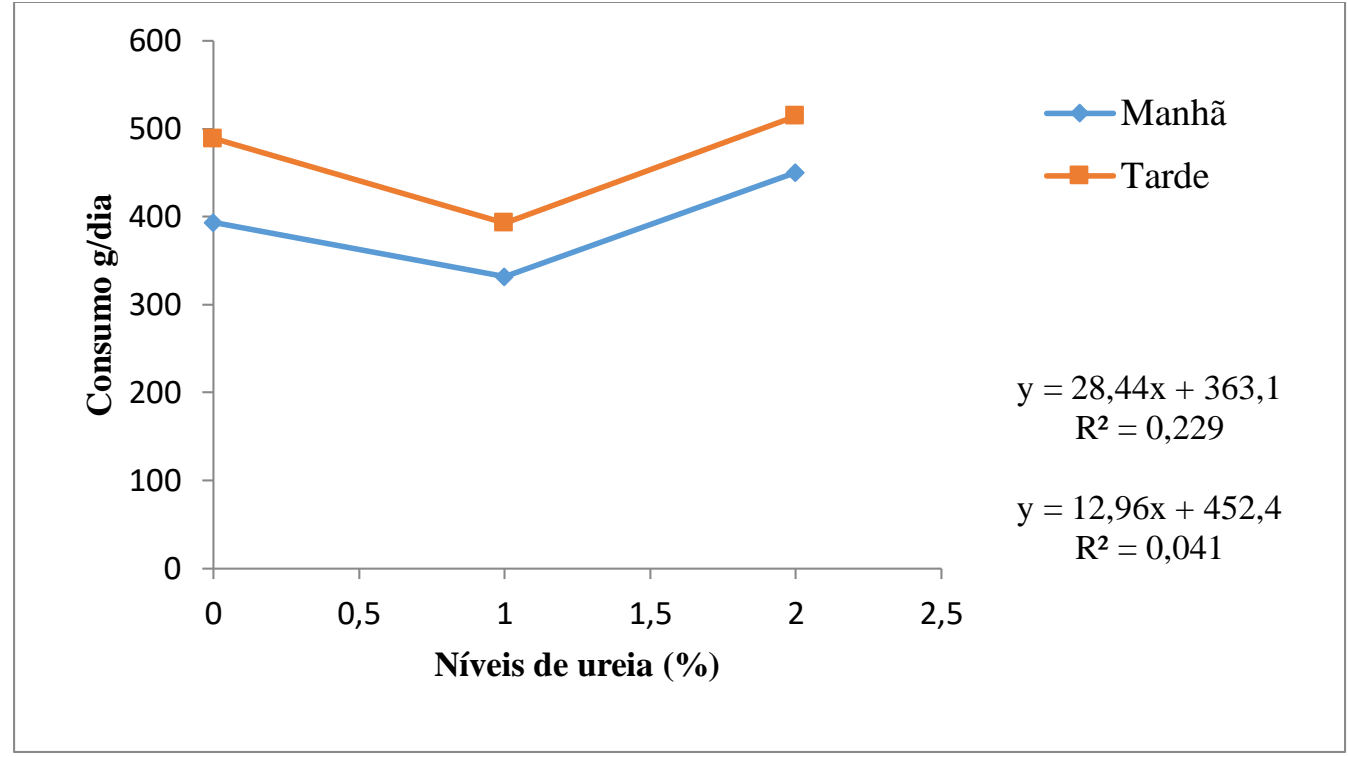

O consumo voluntário dos animais apresentou uma queda ao nível de inclusão de ureia a 1\% (gráfico 1). Salman et al. (1997) o uso de ureia em níveis elevados na dieta, em virtude de sua baixa palatabilidade, pode reduzir o consumo, estando sua quantidade limitada em até $1,0 \%$ na matéria seca (MS) total da dieta. Wilson \& Kennedy (1996) ao fornecerem níveis crescentes de ureia $(1,0 \% ; 1,65 \% ; 2,30 \%$ e $3,0 \%$ na MS total) para novilhos, seja via oral ou por infusão direta no rúmen, verificaram que a ureia deprimiu o consumo quando incluída na dieta em níveis acima de 2,0\%. Neste estudo, porém, os animais submetidos à dieta contendo $2,0 \%$ de ureia tiveram média de consumo maior em relação aos níveis de 0 e $1 \%$.

\section{Conclusões}

Perante o estudo realizado, podemos concluir que a partir da inclusão da ureia em 
diferentes proporções na alimentação dos catetos, a mesma não interfere na aceitabilidade e quantidade consumida pelos animais.

\section{Referências}

ANDRIGUETTO, J.M. et al. Nutrição animal: as bases e os fundamentos da nutrição animal. 3 ed. São Paulo: Nobel, 1981. V.2, 425p.

EDDY, T.A. Food and feeding patterns of the collared peccary in southern Arizona. Journal of Wildlife Management, Menasha, v. 25, n. 3, p. 248-257. 1961.

LANGER, P. Adapttational significance of the forestomach of the collared peccary, Dicotyles tajacu (Mammalia: Artiodactyla). Mammalia, Paris, v.43, p. 235-245, 1979.

MAGALHÃES, K.A.; VALADARES FILHO, S.C.; VALADARES, R.D. et al. Níveis de uréia em substituição ao farelo de soja na dieta de bovinos de origem leiteira em confinamento. 1- Desempenho. In: REUNIÃO ANUAL DA SOCIEDADE BRASILEIRA DE ZOOTECNIA, 39., 2002, Recife. Anais... Recife: Sociedade Brasileira de Zootecnia, 2002a. CD ROM.

Mendes, Alcester. Fornecimento da uréia na dieta de catetos (Pecari tajacu) e uso de isótopo estável ${ }^{15} \mathrm{~N}$ como marcador para estimativa da síntese de nitrogênio microbiano. 2008. Tese (Doutorado em Ciências. Área de concentração: Energia Nuclear na Agricultura e no Ambiente). Centro de Energia Nuclear na Agricultura da Universidade de São Paulo, São Paulo.

NOGUEIRA-FILHO, S. L. G.; LAVORENTI, A. O manejo do caititu ( Tayassu tajacu) e do queixada (T. pecari) em cativeiro. In: PÁDUA, C. V.; BODMER, R. E.; CULLEN JUNIOR, L. (Org). Manejo e conservação de vida Silvestre no Brasil. Brasília: CNPq; Belém: SociedadeCivil Mamirauá, 1997. P. 106-115.

NOGUEIRA-FILHO, S. L. G. et al. Urea as source of non-protein nitrogen to collared peccary. Suiform Soundings, Canberra, v. 6, p.25-29, 2006.

SALMAN, A.K.D.; MATARAZZO, S.V.; EZEQUIEL, J.M.B. et al. Estudo do balanço nitrogenado e da digestibilidade da matéria seca e da proteína de rações para ovinos suplementados com amiréia, uréia ou farelo de algodão. Revista Brasileira de Zootecnia, v. 26, n. 1, p. 170-185, 1997.

SOWLS, Lyle K. Javelinas and other Peccaries: Their biology, management and use. 2. Ed. Tucson: University of Arizona press, 1997.325p.

REECE, W. O. Fisiologia de animais domésticos. São Paulo: Editora Roca, 1996. P. 251.

SWINGLE, R. S.; ARAIZA, A.; URIAS, A. R. Nitrogen utilization by lambs fed wheat straw alone or with supplements containing dried poutry waste, cottonseed meal or urea. Journal 
Animal Science, v. 45, n. 6, p. 1435-41, 1977. Herbage Abstract Farnham Royal, v. 48, n. 9, p. 364, 1997. (Abstract 3171).

WILSON, J.R.; KENNEDY, P.M. Plant and constraints to voluntary feed intake associated with fiber characteristics and particle breakdown and passage in ruminants. Australian Journal of Agricultural Research, v. 47, n. 1, p. 199- 225, 1996. 